\title{
Food supply and the obesity scourge: Is there a relationship?
}

\author{
Lillian Mwanri $^{1^{*}}$, Wendy Foley ${ }^{2}$, John Coveney ${ }^{1}$, Robert Muller ${ }^{1}$, Fiona Verity ${ }^{3}$, Paul R. Ward ${ }^{1}$, \\ Patricia Carter ${ }^{4}$, Philip Mohr ${ }^{5}$, Anne Taylor ${ }^{6}$ \\ ${ }^{1}$ Discipline of Public Health, Flinders University, Adelaide, Australia; ${ }^{*}$ Corresponding Author: lillian.mwanri@flinders.edu.au \\ ${ }^{2}$ Inala Indigenous Health Service, Queensland Health, Inala, Australia \\ ${ }^{3}$ Department of Social Work, Flinders University, Adelaide, Australia \\ ${ }^{4}$ Health Promotion Branch, SA Health, Adelaide, Australia \\ ${ }^{5}$ School of Psychology, University of Adelaide, Adelaide, Australia \\ ${ }^{6}$ Population Research and Outcome Studies Unit, SA Health, Adelaide, Australia
}

Received 7 November 2012; revised 17 December 2012; accepted 23 December 2012

\section{ABSTRACT}

This paper reviews literature on the relationship between food supply and obesity. The focus is on the supply, cost, and variety of food through various types of food outlets and the impact of these factors on obesity in developed countries. The article reveals complex relationships between food supply factors and obesity. A number of factors related to lifestyles including the mobility of populations and the use of motor vehicles greatly reduce the impact of the local environment on family and individual eating patterns. However, obesity is also affected by factors such as the type and density of food outlets, the cost of food, the travel distance and means of transport to the food outlet. While the relationship between food supply and obesity in the literature reveals complex and mixed findings, this paper concludes obesity is complex and food supply is only part of this phenomenon's predictors. Because the relationship between food supply and obesity is mediated by such multiple and complex factors including population behaviours, beliefs, lifestyles, knowledge and both food and physical environments; multiple strategies including policy development and other strategies aimed at manipulating food environments, physical environments, populations' beliefs, behaviours and practices must be considered in searching for evidence to effectively combat obesity.

Keywords: Obesity; Food Supply; Food Outlets; Socio Economic Status; Complex Relationships

\section{INTRODUCTION}

Obesity is a significant public health problem worldwide and high income countries are significantly more affected compared to low and middle income countries $[1,2]$. It is well acknowledged that obesity causes a wide range of chronic conditions including high blood pressure, type 2 diabetes, stroke, cardiovascular disease and certain forms of cancer $[3,4]$ which in turn are primary drivers of health care spending, disability and deaths [3-5]. Treating obesity once it has been established is not easy and the likelihood of childhood obesity transitioning into adulthood obesity is high [6,7]. International and Australian evidence demonstrates upwards trends in total energy supply per capita from the early1980s to date and a concurrent increase of the prevalence of obesity in virtually all developed countries [8].

In Australia, obesity is a significant public health problem and accounts for more than $4 \%$ of the total burden of disease costing the Australian society and governments approximately $\$ 58.2$ billion per year; of which $\$ 49.9$ billion relate to the impact of obesity on quality of life and $\$ 8.3$ billion direct financial costs to the Australian community [9]. However, obesity is not distributed evenly across the population; and is increasingly prevalent among lower socioeconomic groups in most developed nations [9]. With the likelihood of obesity increasing worldwide [10], it is clear that Australia faces escalating costs of obesity, and urgent measures are necessary to combat this scourge.

Similar to other developed countries, evidence indicates that the obesity epidemic in Australia is caused by multiple and complex factors [11,12], including populationwide increase in energy intake, more sedentary lifestyles, reduced active transport, and changed family and social structures that have limited individuals' time and capacity for healthy nutrition and physically active life- 
styles [4,8,9,12]. Knowledge and behaviours of individuals have been conventionally known to explain differentials in populations' weight outcomes. However, geographical area levels of disadvantages and differences in socio economic status (SES) are also considered to be as important in explaining the prevalence of obesity in populations. As interventions attempting to reduce obesity through an individual's focus have had limited success, a branch of obesity research has turned to the impact of local food environments (i.e. food supply, including variety and cost) on obesity [13-15]. The ways in which disadvantaged environments contribute to obesity are, however, not well understood. For example, a review of the literature on the built environment and obesity showed that there has been relatively little focus on food environments compared with physical environments [15].

International literature presents a complex and somewhat contradictory picture of the relationship between food supply and obesity. It is acknowledged that the presence of a food environment which supplies affordable and healthy food is necessary to ensure optimal nutrition, but it is not sufficient to ensure healthy weight outcomes $[15,16]$. Access to the food supply, encompassing economic, social, cultural, time resources and transport, as well as non-food factors, such as lifestyle including physical activity and healthy eating patterns, are all important determinants of weight outcomes.

The aim of the review is to examine and evaluate the relationship between overweight/obesity and factors such as variety and cost of food, and type of food retail outlets in order to provide some understanding of the relationship between food supply and weight status.

\section{METHODS}

A systematic search of English literature was conducted. The following databases were searched for publications for the period of 2000 to 2010: Web of Science/ Knowledge; Informit; APAIS; Sociological Abstracts; PAIS; Science Direct; Expanded Academic (Gale) and Proquest. The following search terms were used in combination and/or singly: food retail, food environment, neighbourhood, food cost, food price, socio economic status, obesity and overweight. References cited in relevant publications were also reviewed. Publications relating to developing countries, clinical aspects of obesity or obesity treatment, child obesity, and food supply in schools through charitable organisation sand government programs were not included. Because of methodological differences and limited number of articles providing high level of evidence, a narrative as opposed to systematic review was conducted. Following a systematic literature search as described above, content analysis was performed and findings were grouped according to emerging themes [17].

\section{RESULTS}

Three emerging themes from literature are described below and include:

- Supply of healthy food and obesity,

- Supply of less healthy food and obesity, and

- Cost of food and obesity.

\subsection{Supply of Healthy Food and Obesity}

Different types of food stores are used as markers of healthy or less healthy food supply [18-21]. Indicators including the presence, the number and the concentration (density) [18-24] of supermarkets in abounded geographical have been used as a measure of the food supply for local populations. While fruit and vegetables to res are also used to indicate the supply of healthy food, conveniences to res are often used to indicate less healthy food choices. The presence of supermarkets has been found to be significantly associated with a lower prevalence of overweight. Morland and others [18] found a $24 \%$ lower prevalence of obesity in areas with at least one supermarket compared to areas without supermarkets. In the review that assessed neighbourhood food supply and obesity in the USA, Black and Macinko [22] demonstrated that, although neighbourhood food availability is associated with food choices and/or lack of these, especially for fruit and vegetables among low income households, the net impact of neighbourhoods food supply on obesity remains unresolved. Positive correlations have also been noted between higher levels of obesity and greater distance to primary grocery stores, high availability of conveniences to res than supermarkets and higher fruit and vegetable price indexes [26]; the latter perhaps indicating that many people who have healthier weight status can also afford to pay more for fruit and vegetables.

The presence of conveniences to res has been found to be significantly associated with a higher prevalence of obesity [18]. Similar findings have been reported in a study examining the association between the availability of food stores (including supermarket chains, non-chain supermarkets, convenience stores and other grocery stores) and adolescent weight outcomes [23]. The availability of supermarket has been correlated with adolescents' weight outcomes, with each additional chain supermarket per 10,000 people, associated with a weight reduction of 0.11 Body Mass Index (BMI) units and a 0.6 percent lower prevalence of overweight. Of importance to note is the association between supermarket availability and weight of African American adolescents, which has been estimated to be three times greater than those from a White or Hispanic background. Greater availability of convenience stores has been recorded to best artistically associate with higher weight, with additional convenience store 
per 10,000 people, associated with an increase of 0.03 BMI units and increased the prevalence of overweight by 0.15 percent [18].

Wang and colleagues [19] have reported an association between local food store characteristics and weight outcomes, with adults living in low socio economic neighbourhoods having a higher mean Body Mass Index (BMI) (0.6 BMI units) than those in high socio economic neighbourhoods in California [19]. A high concentration of small grocery stores has also been associated with higher BMI, however, individual level factors including gender, age, ethnicity, individual SES, smoking, physical activity and knowledge of nutrition had great influences of obesity [19].

Studies from across the world have reported that large supermarkets provide the wide strange of food items for the lower prices compared to smaller stores that supply less healthy food choices [24-33]. Furthermore, it has been argued that commercial preferences for placing supermarkets in areas with higher socio economic status disadvantages certain populations groups, in particular ethnic groups including African Americans [23,29]. Limited access to supermarkets means that disadvantaged people, who generally have poor access to both public and private transport, have to travel longer distances to obtain food supply [21,25,26].

Due to the heterogeneity of food supply found in some countries, for example in Australian suburbs, fruit and vegetable intake at the individual rather than at the neighbourhood (suburb) level suggested the need to focus on food purchasing considerations for health and nutrition knowledge, rather than neighbourhood food supply [20, 33]. It is also acknowledged that, individual or household factors have more impact on food purchasing than does the food store environment [20,33]. However, as nutrition education alone does not provide sufficient means to facilitate healthy eating improvements in poor households, this form of education for lower income people is unlikely to improve access to healthy foods, or weight status, although it may make some contribution [34].

\subsection{Supply of Less Healthy Food and Obesity}

The supply of less healthy food has frequently been associated with the availability of ready-to-eat food, including fast food restaurants (FFRs). Several studies have acknowledged that FFRs' products comprise high density energy [35,36]. There is also a noted relationship between high proliferation of FFRs and high obesity rates in areas with low socio economic status [13,37-40]. Researchers in New York linked their strong findings of higher density of FFRs (including chains and independent perators) in predominantly black neighbourhoods (based on census blocks), with the known higher prevalence of obe- sity among black Americans [41]. A Canadian study of fast food availability also reported obesity to be significantly higher among lower socio economic neighbourhood, with increasing availability observed in areas of successively higher proportions of unemployment, lowincome and renters [42]. Studies by Burns and Inglis [31] and Reid path and others [37] in Australia demonstrated a dose-response relationship between socio economic status (SES), the density of fast-food outlets and obesity prevalence. Reidpath and others [37] reported 2.5 times the exposure to fast food outlets in people with low SES than people in the highest SES areas in Australia. This was supported by Burns and Ingl is who reiterated that $t$ less advantaged people in a Municipality in Melbourne had a more readily available supply of fast-food.

Although these findings provide a plausible hypothesis that there is a relationship between ease of access to fast food restaurants with the development of obesity, they are far from conclusive. For example, the direction of causation is not clear, because the menus and prices at FFR may results from the demands of an increasingly obese population rather than being a direct cause of obesity. It is also plausible to suggest that other predictive variables including sedentary lifestyle characteristics, age of the population, ethnicity, smoking and others may play significant part in these phenomena. Additionally, other studies have not provided conclusive evidence of the direct relationship between fast food outlet concentrations with population obesity rates [22,43-46]. Variations in study methodology may also contribute to these inconclusive findings. Many studies have no direct measure of consumption or obesity but draw conclusions about fast food supply and obesity using ecological data to complement neighbourhood mapping of fast food access [23,42]. Studies in New Zealand [45] and the USA [14] reported that there was association between obesity and fast food consumption through linking population health data for weight outcomes of individuals by area through mapping to determine the density of, or distance to FFRs without any direct measures of actual fast food consumption.

It is reasonable to conclude that, studies of the food supply in relation to fast food availability paint a complex picture with equivocal results in terms of the relationship between neighbourhood fast food availability and obesity, and there fore, it is difficult without further research to make solid conclusions about the association of supply of less healthy food with obesity.

\subsection{Food Cost and Obesity}

Several studies recognise that energy-dense food provides cheaper energy while fruit, vegetables, lean meat and fish continue provide more expensive energy $[47,48]$. Refined grains, added sugar and fats, potatoes and beans 
continue to provide cheaper energy while fruit, vegetables, lean meat and fish continue to provide more expensive energy. A body of research on food cost contends that the high cost of low energy-dense but nutrient-rich food compared with energy-dense but nutrient-poor food, impacts on weight status of people with less money to spend on food. Furthermore, international studies on the price of energy-dense versus nutrient-dense foods and the cost effect on food selection and weight outcomes demonstrated that, if food selection is restricted by cost considerations, energy-dense but nutrient-poor diets are selected $[43,47]$. This was first shown through diet-modelling studies [49] then later through epidemiological studies, which demonstrated that freely "chosen" low cost diets in France tend to be energy-dense but nutrient-poor [50,51].

A variety of studies have used diet records to estimate the relationship between food consumption and food costs [50,51]. Findings reveal an indirect relationship between energy costs and energy dense dietary intakes, with those in the highest quartile of energy cost reported to have lower energy intakes and more nutrient-dense diets which implies that healthier diets cost more. Energy-dense foods have been found to be the less expensive as well as the most resistant to inflation [47]. A high price of fruit and vegetables compared with fats and sweets has been observed in few studies [48,52]. Various market basket surveys demonstrate the higher cost of recommended, healthy foods. For example, a study in California assessed the price of the USDA's Thrifty Food Plan basket a healthier market basket containing foods with higher fibre and lower fat in 25 large and small urban grocery stores and found price increase be three-times over a one-year period [27]. In addition, the cost of the healthier basket for a 2-week shopping list for a family was more expensive (approximately 20 percent more) than "regular" options and that healthier food choices were less available in the smaller stores. Smaller stores are more easily accessible for people without private transport, and this could be "a formidable deterrent" for low-income consumers [27, 32]. Low-income households may be forced to select energy-dense foods, including higher proportions of foods containing grains, added sugars and fats. Studies in Australia indicate the price of food varied according to proximity tour ban centres - the mean cost of a healthy basket of food was 24 percent higher in very remote stores and 33 percent higher in the most remote stores, compared to a similar food basket in major cities [48]. A subsequent longitudinal study of changes in food prices between 1989 and 2007 also found that the price of healthier foods generally rose more steeply than the price of unhealthy foods [53].

A number of nutrition practitioners and researchers, including in Australia work on the premise that cost bar- riers to healthy eating and weight maintenance are perceived rather than real $[33,54]$. However, it has also been argued that regardless of price, such diets could be difficult to follow as they may be based around unfamiliar foods (e.g. liver, dried beans), and may deviate from social food norms. Additionally, they may be considered unpalatable and taking more preparation time $[55,56]$. It is clear that price has an influence on food purchasing decisions [57] and dependence on less nutritious but more economical and socially acceptable foods. This could therefore contribute to disproportionate rates of obesity among groups with limited economic means [51]. A 20year longitudinal study on dietary behaviours that examined both direct effects of a price change on intake of a particular food (own price elasticity) and the indirect effects of substitutes and complementary foods in the USA found that altering of prices was associated with changes in daily product intakes, even in disadvantaged populations. For example, a study by Duffey and others [58] found that a $10 \%$ increase of soda or pizza was associated with lower consumptions of these items and therefore lowered daily energy intakes associated with these foods, leading to changes in bodyweight in low socio economically deprived populations. As such this study suggested that policies aimed at altering the price of soda or pizza could be effective mechanism to support consumption of health diets in populations and lead to healthier weight outcomes [58].

\section{DISCUSSION}

Determining the impact of local food supply on obesity is a very complex task. It is reasonable to expect that although food supply may play part, it may not be a sole predictor of obesity in populations. For example, in a food security review, White [32] indicated that there was only weak evidence that food retailing in isolation affected diet and therefore, this indicator alone was unlikely to have a profound impact on obesity. In agreement with White, [32] arrange of researchers have suggested that retail availability and access may not be the only necessary predictor of improving diet quality in the future $[19,22$, $45,46]$.

There is also a significant gap in the literature that negates the understanding of the food procurement habits of food-insecure, low-income people [22,53]. Particularly relevant to this would be an examination of the trade-offs between the various resources required to access the food supply, including time, transport and income. The complexity of these trade-offs and how people make decisions about where, when and how to acquire food is relatively under investigated [22]. Much of the literature is concerned with "objective" measures such as the density of particular types of food stores or the distances people 
travel to reach them and the cost of food or energy-costs. Too little of the literature is concerned with subjective accounts of people's interactions with the food supply, although information on people's shopping habits is an important complement to the mapping research that has been conducted [59]. For example, Drewnowski [60] recommends future research that considers the relative costs of healthy and unhealthy diets, which should be examined in relation to the purchasing power of consumers. However, it has also been suggested that policy frameworks that increase the prices of unhealthy foods and beverages in order to shift the behaviours towards healthier diet consumptions may be effective strategies to reduce consumption of unhealthy food and improve health weight in the population $[47,58,61]$. It is plausible therefore to conclude that this the area of food price policies needs further research.

\section{CONCLUSIONS}

This review reveals complex relationships between food supply factors and obesity. Due to different methodological approaches, it was often the case mixed findings were reported in different studies, and at times, one study not supporting another in the same area. The evidence however exists suggestive of a relationship between selective food supply and obesity including when the cost of energy dense foods were priced at high level [58]. This conclusion is believed to be strong because longitudinal studies tend to provide better conclusions when compared with cross sectional studies [58]. Given that the food environments between countries and even within countries are likely to be different, it is not surprising that the effects of environments on obesity might be inconclusive. It might seem obvious that where one lives greatly influences the quality of food consumed, and therefore obesity. However, in some countries-and Australia is a good example-mobility of populations and use of motor vehicles greatly reduces the impact of the local environment on family and individual eating patterns. In other countries however, especially urban parts of North America and the UK, mobility through use of private transport is restricted.

While notable to paint clearly and decisively the relationships between food supply and obesity, our review is helpful in cautioning against simplistic assumptions about the impact of where one lives and healthy food supplies.

It should also be noted that many studies in this review are cross-sectional, including some secondary analyses of existing data. The use of cross-sectional studies, however, limits causal inferences concerning obesity and the food supply [16,32]. It is therefore plausible to conclude that, while food supply may play an important role in population obesity, obesity is a complex phenomenon which includes multiple complex factors and interactions. Because the relationship between food supply and obesity is mediated by such multiple and complex factors; multiple strategies including policy development and other strategies aimed at manipulating food environments, physical environments, populations' beliefs, behaviours and practices must be considered in searching for evidence to effectively combat obesity.

\section{REFERENCES}

[1] Organisation for Economic Co-Operationand Development (2009) Health at glance. OECD Indicators, Paris.

[2] Al-Othaimeen, A.I., Al-Nozha, M. and Osman, A.K. (2007) Obesity: An emerging problem in Saudi Arabia Analysis of data from National Nutritional Survey. Eastern Mediterranean Health Journal, 13, 441-447.

[3] Australian Government Department of Health and Aging (2005) Consultation draft of the national chronic disease strategy. Australian Government, Canberra.

[4] World Health Organization (WHO) (2000) Obesity: Preventing and managing the global epidemic. WHO, Geneva.

[5] Sturm, R. (2002) The effects of obesity, smoking and drinking on medical problems and costs. Health Affairs, 21, 245-253. doi:10.1377/hlthaff.21.2.245

[6] Musaiger, A. (2004) Overweight and obesity in the Eastern Mediterranean region: Can we control it. East Mediterranean Health Journal, 10, 789-793.

[7] Lobstein, T., Baur, L. and Uauy, R. (2004) Obesity in children and young people: A crisis in public health. Obesity Reviews, 5, 4-85. doi:10.1111/j.1467-789X.2004.00133.X

[8] Silventoinen, K., Sans, S., Tolonen, H., Monterde, D., Kuulasmaa, K., Kesteloot, H. and Tuomilehto, J. (2004) Trends in obesity and energy supply in the WHOMONICA Project. International Journal of Obesity and Related Metabolic Disorders, 28, 710-718. doi:10.1038/sj.ijo.0802614

[9] Common Wealth of Australia (2009) Australia: The healthiest country by 2020: Obesity in Australia. Preventative Health Taskforce, ACT, Canberra.

[10] World Health Organization (2000) Obesity: Preventing and managing the global epidemic. WHO, Geneva

[11] Renzaho, A., Swinburb, B. and Burns, C. (2008) Maintenance of traditional cultural orientation is associated with lower rates of obesity and sedentary behaviours among African migrant children to developed countries. International Journal of Obesity, 32, 594-600. doi:10.1038/ijo.2008.2

[12] O’brien, K. and Webbie, K. (2003) A real Australians gaining weight: Differentials in overweight and obesity among adults, 1989-1990 to 2001. Australian Institute of Health and Welfare, Canberra.

[13] Maddock, J. (2004) The relationship between obesity and the prevalence of fast food restaurants: State-level analysis. American Journal of Health Promotion, 19, 137-143. doi:10.4278/0890-1171-19.2.137 
[14] Mehta, N. and Chang, V.W. (2008) Weight status and restaurant availability: A multilevel analysis. American Journal of Preventive Medicine, 34, 127-133. doi:10.1016/j.amepre.2007.09.031

[15] Papas, M., Alberg, A.J., Ewing, R., Helzlsouer, K.J., Gary, T.L. and Klassen, A.C. (2007) The built environment and obesity. Epidemiologic Reviews, 29, 129-143. doi:10.1093/epirev/mxm009

[16] Ford, P. and Dzewaltowski, D.A. (2008) Disparities in obesity prevalence due to variation in the retail food environment: Three testable hypotheses. Nutrition Reviews, 66, 216-228. doi:10.1111/j.1753-4887.2008.00026.x

[17] Gasparyan, A.Y., Ayvazya, L., Blackmore, H., Kitas, G.D. (2011) Writing a narative biomedical review: Considerations for authors, peer reviewers, and editors. Rheumatology International, 31, 1409-1417. doi:10.1007/s00296-011-1999-3

[18] Morland, K., DiezRoux, A. and Wing, S. (2006) Supermarkets, other food stores, and obesity: The atherosclerosis risk in communities study. American Journal of Preventive Medicine, 30, 333-339. doi:10.1016/j.amepre.2005.11.003

[19] Wang, M.C., Kim, S., Gonzalez, A.A., MacLeod, K.E. and Winkleby, M.A. (2007) Socioeconomic and food-related physical characteristics of the neighbourhood environment are associated with body mass index. Journal of Epidemiology \& Community Health, 61, 491-498. doi:10.1136/jech.2006.051680

[20] Ball, K., Crawford, D. and Mishra, G (2009) Socio-economic in equalities in women's fruit and vegetable intakes: A multi level study of individual, social and environmental mediators. Public Health Nutrition, 9, 623-630.

[21] Sharkey, J.R. and Horel, S. (2008) Neighbourhoods socioeconomic deprivation and minority composition are associated with better potential spatial access to the groundtruthed food environment in a large rural area. Journal of Nutrition, 138, 620-628.

[22] Black, J. and Macinko, J. (2008) Neighbourhoods and obesity. Nutrition Reviews, 66, 2-20. doi:10.1111/j.1753-4887.2007.00001.x

[23] Powell, L.M., Auld, M.C., Chaloupka, F.J., O’Malley, P.M. and Johnston, L.D. (2007) Associations between access to food stores and adolescent body mass index. American Journal of Preventive Medicine, 33, S301-S307. doi:10.1016/j.amepre.2007.07.007

[24] Guy, C.M. and David, G. (2004) Measuring physical access to "healthy foods" in areas of social deprivation: A case study in Cardiff. International Journal of Consumer Studies, 28, 222-234. doi:10.1111/j.1470-6431.2003.00340.x

[25] Inagami, S., Cohen, D.A., Finch, B. and Asch, S.M. (2006) You are where you shop: Grocery store locations, weight, and neighborhoods. American Journal of Preventive Medicine, 31, 10-17. doi:10.1016/j.amepre.2006.03.019

[26] Powell, L.M., Slater, S., Mirtcheva, D., Bao, Y. and Chaloupka, F.J. (2007) Food store availability and neighbourhoods characteristics in the United States. Preventive
Medicine, 44, 189-195. doi:10.1016/j.ypmed.2006.08.008

[27] Jetter, K.M. and Cassady, D. (2006) The availability and cost of healthier food alternatives. American Journal of Preventive Medicine, 30, 38-44. doi:10.1016/j.amepre.2005.08.039

[28] Glanz, K., Sallis, J.F., Saelens, B.E. and Frank, L.D. (2007) Nutrition environment measures survey in stores (NEMS-S): Development and evaluation. American Journal of Preventive Medicine, 32, 282-289. doi:10.1016/j.amepre.2006.12.019

[29] Baker, E.A., Schootman, M., Barnidge, E. and Kelly, C. (2006) The role of race and poverty in access to foods that enable individuals to adhere to dietary guidelines. http://www.cdc.gov/pcd/issues/2006/jul/05_0217.htm

[30] Powell, L.M., Chaloupka, F.J. and Bao, Y. (2007) The availability of fast food and full-service restaurants in the United States: Associations with neighbourhoods characteristics. American Journal of Preventive Medicine, 33, 240-245. doi:10.1016/j.amepre.2007.07.005

[31] Burns, C. and Inglis, A.D. (2007) Measuring food access in Melbourne: Access to healthy and fast food by car, bus and foot in an urban municipality in Melbourne. Health \& Place, 13, 877-885. doi:10.1016/j.healthplace.2007.02.005

[32] James, P.T., Leach, R., Kalamara, E. and Shayeghi, M. (2001) The worldwide obesity epidemic. Obesity Research, 9, 228S-233S.

[33] Giskes, K., Van Lenthe, F., Brug, J., Mackenbach, J.P. and Turrell, G. (2007) Socioeconomic inequalities in food purchasing: The contribution of respondent-perceived and actual (objectively measured) price and availability of foods. Preventive Medicine, 45, 41-48. doi:10.1016/j.ypmed.2007.04.007

[34] Glanz, K. (1985) Nutrition education for risk factor reduction and patient education. A review. Preventive Medicine, 14, 721-752. doi:10.1016/0091-7435(85)90069-6

[35] Burns, C., Jackson, M., Gibbons, C. and Stoney, R.M. (2002) Foods prepared outside the home: Association with selected nutrients and body mass index in adult Australians. Public Health Nutrition, 5, 441-448. doi:10.1079/PHN2001316

[36] Bowman, S. and Vinyard, B.T. (2004) Fast food consumption of US adults: Impaction energy and nutrient intakes and overweight status. Journal of the American College of Nutrition, 23, 163-168.

[37] Reidpath, D.B.C., Garrard, J., Mahoney, M. and Townsend, M. (2002) An ecological study of the relationship between social and environmental determinants of obesity. Health \& Place, 8, 141-145. doi:10.1016/S1353-8292(01)00028-4

[38] Cummins, S., McKay, L. and MacIntyre, S. (2005) McDonald's restaurants and neighbourhoods deprivation in Scotland and England. American Journal of Preventive Medicine, 29, 308-310. doi:10.1016/j.amepre.2005.06.011

[39] Maddock, J. (2004) The relationship between obesity and the prevalence of fast food restaurants: State-level analysis. American Journal of Health Promotion, 19, 137-143. 
[40] Macdonald, L., Cummins, S. and Macintyre, S. (2007) Neighbourhood fast food environment and area deprivation-substitution or concentration? Appetite, 49, 251-254. doi:10.1016/j.appet.2006.11.004

[41] Kwate, N.O.A. (2008) Fried chicken and fresh apples: Racial segregation as a fundamental cause of fast food density in black neighborhoods. Health \& Place, 14, 3244. doi:10.1016/j.healthplace.2007.04.001

[42] Hemphill, E, Raine, K., Spence, J.C. and Smoyer-Tomic, K.E. (2008) Exploring obesogenic food environments in Edmonton, Canada: The association between socioeconomic factors and fast food outlet access. American Journal of Health Promotion, 22, 426-432. doi:10.4278/ajhp.22.6.426

[43] Jeffery, R., Baxter, J., McGuire, M. and Linde, J. (2006) Are fast food restaurants an environmental risk factor for obesity? International Journal of Behavioral Nutrition and Physical Activity, 3, 35. doi:10.1186/1479-5868-3-2

[44] Burdette, H.L. and Whitaker, R.C. (2004) Neighborhoods playgrounds, fast food restaurants, and crime: Relationships to overweight in low-income preschool children. Preventive Medicine, 38, 57-63. doi:10.1016/j.ypmed.2003.09.029

[45] Pearce, J., Hiscock, R., Blakely, T. and Witten, K. (2009) A national study of the association between neighbourhood access to fast food outlets and the diet and weight of local residents. Health \& Place, 15, 193-197. doi:10.1016/j.healthplace.2008.04.003

[46] Simmons, D., McKenzie, A., Eaton, S., Cox, N., Khan, M.A., Shaw, J. and Zimmet, P. (2005) Choice and availability of take away and restaurant food is not related to the prevalence of adult obesity in rural communities in Australia. International Journal of Obesity, 29, 703-710. doi:10.1038/sj.ijo.0802941

[47] Drewnowski, A. and Darmon, N. (2005) The economics of obesity: Dietary energy density and energy cost. The American Journal of Clinical Nutrition, 82, 265-273.

[48] Queensland Health (2006) The 2006 Healthy Food Access Basket (HFAB) survey. Queensland Government, Brisbane, 2006.

[49] Drewnowski, A. and Specter, S.E. (2004) Poverty and obesity: The role of energy density and energy costs. The American Journal of Clinical Nutrition, 79, 6-16.

[50] Drewnowski, A., Darmon, N. and Briend, A. (2004) Replacing fats and sweets with vegetables and fruits: A question of cost. American Journal of Public Health, 94, 1555-1559. doi:10.2105/AJPH.94.9.1555
[51] Andrieu, E.D.N. and Drewnowski, A. (2006) Low-cost diets: More energy, fewer nutrients. European Journal of Clinical Nutrition, 60, 434-436. doi:10.1038/sj.ejcn.1602331

[52] Monsivais, P. and Drewnowski, A. (2007) The rising cost of low-energy-density foods. Journal of the American Dietetic Association, 107, 2071-2072. doi:10.1016/j.jada.2007.09.009

[53] Burns, C. and Sacks, G. (2008) Longitudinal study of consumer price index (CPI) trends in core and non-corefoods in Australia. Australian and New Zealand Journal of Public Health, 32, 450-453. doi:10.1111/j.1753-6405.2008.00278.x

[54] Inglis, V.B.K. and Crawford, D. (2008) Socioeconomic variations in women's diets: What is the role of perceptions of the local food environment? Journal of Epidemiology \& Community Health, 62, 191-197. doi:10.1136/jech.2006.059253

[55] Drewnowski, A. and Barratt-Fornell, A. (2004) Do healthier diets cost more? Nutrition Today, 39, 161. doi:10.1097/00017285-200407000-00006

[56] Rose, D. (2007) Food stamps, the thrifty food plan, and meal preparation: The importance of the time dimension for US nutrition policy. Journal of Nutrition Education and Behavior, 39, 226-232.

[57] Beydoun, M., Powell, L.M. and Wang, Y. (2008) The association of fast food, fruit and vegetable prices with dietary in takes among US adults: Is there modification by family income? Social Science \& Medicine, 66, 22182229. doi:10.1016/j.socscimed.2008.01.018

[58] Duffey, K., Gordon-Larse, P., Shikany, J.M., Guikey, D., Jacobs, D.R. and Popkin, B.M. (2010) Food price and diet and health outcomes. Twenty years of the Cardia Study. Archives of Internal Medicine, 170, 420-426. doi:10.1001/archinternmed.2009.545

[59] Morland, K., Wing, S. and Diex-Roux, A. (2002) The contextual effect of the local food environment on residents' diets: The atherosclerosis risk in communities study. American Journal of Public Health, 92, 1761-1767. doi:10.2105/AJPH.92.11.1761

[60] Drewnowski, A. (2007) The real contribution of addedsugars and fats to obesity. Epidemiologic Reviews, 29, 160171. doi:10.1093/epirev/mxm011

[61] McColl, K. (2009) "Fat taxes" and financial crisis. The Lancet, 373, 797-798. doi:10.1016/S0140-6736(09)60463-3 